\title{
PATHOGENESIS OF GANGRENE FOLLOWING INTRA-ARTERIAL INJECTION OF DRUGS: A NEW HYPOTHESIS
}

\author{
R.L. KNILL AND D. Evans
}

\section{INTRODUCTION}

ALthough less commonly encountered in the operating room, the intra-arterial injection of locally destructive drugs continues to be a significant medical problem. With the frequent administration of drugs intra-vascularly, inadvertent intraarterial injections are bound to occur. We have witnessed the accidental injection of several drugs into a radial artery cannula in an Intensive Care Unit. There are now several reports of addicts having injected drugs into arteries while attempting to "main-line"." The spectrum of drugs known to have produced gangrene now includes barbiturates, phenothiazines, narcotics, amphetamines and ether (Table I).$^{1-6}$

\section{TABLE I}

Locally Necrotizing and Benign Drugs INJECTED INTRA-ARTERIALLY IN MAN ${ }^{1-7}$

\begin{tabular}{ll}
\hline \multicolumn{1}{c}{ Necrotizing } & \multicolumn{1}{c}{ Benign* } \\
\hline Thiopentone & Heparin \\
Methohexitone & Protamine \\
Quinalbarbitone & Procaine \\
Pentobarbitone & Lidocaine \\
Amobarbitone & Tolazoline \\
Chlorpromazine & Fluorouracil \\
Promethazine & \\
Promazine & \\
Meperidine & \\
Heroin & \\
Amphetamine & \\
Ether & \\
Sulfobromophthalein & \\
\hline
\end{tabular}

"Harmlessness of these drugs is established only for clinically used dosages and concentrations.

Despite considerable investigation, the pathogenesis of gangrene following intra-arterial injection of these substances is uncertain and the rationale of various forms of therapy is debated. ${ }^{1-5,8}$ It has been known for many years that arteries and arterioles exposed to 5 per cent or 10 per cent thiopentone react with varying degrees of inflammation of their endothelial, sub-endothelial and muscle layers. ${ }^{4}$ It was originally suggested that inflammatory swelling progressively encroached upon vessel lumens, and as a result of stasis and intimal damage, thrombosis

From the Department of Anaesthesia, University of Toronto and Toronto Western Hospital.

'Present address: Department of Anaesthesia, University of Westem Ontario, London, Ontario, Canada. 
eventually occurred. ${ }^{8}$ More recently it has been proposed that injected thiopentone forms crystals of insoluble acid, which when undiluted in the arterial system, mechanically block the microcirculation, ${ }^{9}$ or initiate acute thrombosis therein. ${ }^{10}$ These latter theories are based on in vitro data; immediate blockage of small vessels has not been shown to occur in vivo.

A number of drugs have been injected intra-arterially in man, both accidentally and intentionally. Some drugs are noxious and may result in gangrene, while others are relatively safe (Table I). Following the intra-arterial injection of any of the noxious agents, the local clinical and pathological changes are remarkably similar, ${ }^{1-0}$ suggesting that a common physical or chemical property might account for their effects. If so, that property should be consistent with irreversible damage occurring during the brief contact of drug with the blood vessel walls.

Noting that the necrotizing drugs of Table I were also the more lipid soluble, ${ }^{11}$ we hypothesized that at any given concentration, the lipid or membrane solubility of a drug could determine its potential for inducing gangrene. It is well known that highly membrane soluble drugs can be haemolytic; in high concentrations, they quickly lyse red blood cells. ${ }^{12}$ They have a similar effect on other cell types in vitro. ${ }^{13}$ This lytic effect depends upon the presence of the drug above a critical concentration in the cell membrane. ${ }^{12}$ If injected intra-arterially, membrane soluble drugs would achieve high concentrations in the plasma membranes of vascular endothelial cells. A lytic effect here could initiate a chain of events terminating with intravascular thrombosis and gangrene.

Our experiments consisted of intra-arterial injections of diazepam and ketamine hydrochloride into the pinna of the rabbit. Diazepam and ketamine have markedly different solubility characteristics, ${ }^{14}$ diazepam being much more lipid soluble than ketamine. The pinnas injected with diazepam all became gangrenous, while those injected with ketamine did not. In the diazepam-injected ears, there was no early vascular obstruction, but endothelial cell damage was evident within hours. The results suggest that the fundamental mechanism leading to gangrene is disruption and leakage of endothelial plasma membranes.

\section{METHOD}

A standard protocol was followed in each of three experimental sections.

Thirty-one New Zealand white rabbits (weight 2 to 4 kilos) were anaesthetized with 50 per cent nitrous oxide and 2 per cent to 3 per cent halothane. Their pinnas were prepared surgically and through a vertical incision at the base of each pinna, the central artery was exposed. A 25-gauge needle was inserted into the artery and time was allowed for the reactive spasm to subside. Halothane was discontinued and, as the level of anaesthesia was lightening, an injection of drug or saline was made slowly and continuously over a period of one minute. Following the injection, the skin was sutured and anaesthesia was discontinued.

\section{Routine Pathological Studies}

Twenty-seven animals ( 54 ears) were divided into three groups:

(a) Six ears were injected with saline $1 \mathrm{cc}$ and observed for two weeks. 
(b) Twelve ears were injected with ketamine hydrochloride ( 1 per cent) 2 to $5 \mathrm{mgm}$ per kilo, and observed for two weeks.

(c) Thirty-six ears were injected with diazepam ( 0.5 per cent), 0.2 to $0.5 \mathrm{mgm}$ per kilo. Twenty-four of these ears were observed grossly for two weeks; the remaining 12 were removed surgically at varying periods following injection ( 6 hours, 5 days, 10 days and 14 days ), and preserved in formalin. Subsequently, cross-sections were taken from these ears in two areas; at the site of injection, and at the junction of the middle and distal thirds. The sections were dehydrated, embedded in paraffin, stained with haematoxylin and eosin, and examined with a light microscope. Two control saline injected ears were prepared in identical fashion.

\section{Doppler Flow Studies}

Two rabbits were anaesthetized and, prior to injection, a Parks 506 Directional Doppler Flow Detector was placed alternatively over the central and peripheral arteries of the pinna. At each location, the doppler signal was recorded on a polygraph machine. Both ears of each animal were injected with diazepam ( 0.5 per cent), $0.5 \mathrm{mgm}$ per kilo, and the Doppler was again applied to the same areas of the pinna. Attempts were made to record signals every few minutes over the ensuing hour, and then every two or three days for two weeks.

\section{Electron Microscopic Study}

Two rabbits were anaesthetized and three ears injected with diazepam (0.5 per cent) $0.5 \mathrm{mgm}$ per kilo. The fourth was injected with saline. Four hours after injection the animals were re-anaesthetized and multiple one millimeter cubed blocks were cut from the periphery of the ear. The blocks were immediately fixed in 3 per cent glutaraldehyde in cacodylate buffer ( $\mathrm{pH} 7.2)$. After two hours, they were washed with cacodylate buffer in sucrose ( $\mathrm{pH} \mathrm{6.8),} \mathrm{and}$ stored overnight. After another washing, immersion in Palade's fixative (2 per cent osmium tetroxide) and dehydration, they were embedded in Epon, sectioned, stained with toluidine blue, and reviewed by light microscopy for presence of capillaries. Selected blocks were sectioned with a diamond knife on a microtome. Sections 500 Angstrom thick were mounted on a 300-mesh copper grid, and stained with uranyl acetate and lead. These were examined and photographed with a Philips 300 electron microscope.

\section{ResUlts}

\section{Routine pathological studies}

Experimental results are summarized in Table II. There were no pathological changes following intra-arterial saline or ketamine. Intra-arterial diazepam, at the dosages used, consistently resulted in necrosis and gangrene (Figure 1).

Immediately following an injection of diazepam, there was a period of obvious vaso-constriction, lasting from a few minutes up to half an hour. During this time, the pinna was dusky and cool. Oedema developed gradually over the subsequent 48 hours, and the pinna remained swollen and dusky for the ensuing week and a 
TABLE II

Experimental Results

\begin{tabular}{|c|c|c|c|}
\hline Drug & Dose & $\begin{array}{l}\text { Number of } \\
\text { ears injected }\end{array}$ & $\begin{array}{l}\text { Number of } \\
\text { ears gangrenous }\end{array}$ \\
\hline Saline & $1 \mathrm{cc}$ & 6 & 0 \\
\hline Diazepam & $0.2-0.5 \mathrm{mgm} / \mathrm{kg}$ & 30 & $30^{*}$ \\
\hline $\begin{array}{l}\text { Ketamine } \\
\text { hydrochloride }\end{array}$ & $2-5 \mathrm{mgm} / \mathrm{kg}$ & 12 & 0 \\
\hline
\end{tabular}

*Probability of no difference from control $<0.01$ (test of difference between independent proportions).

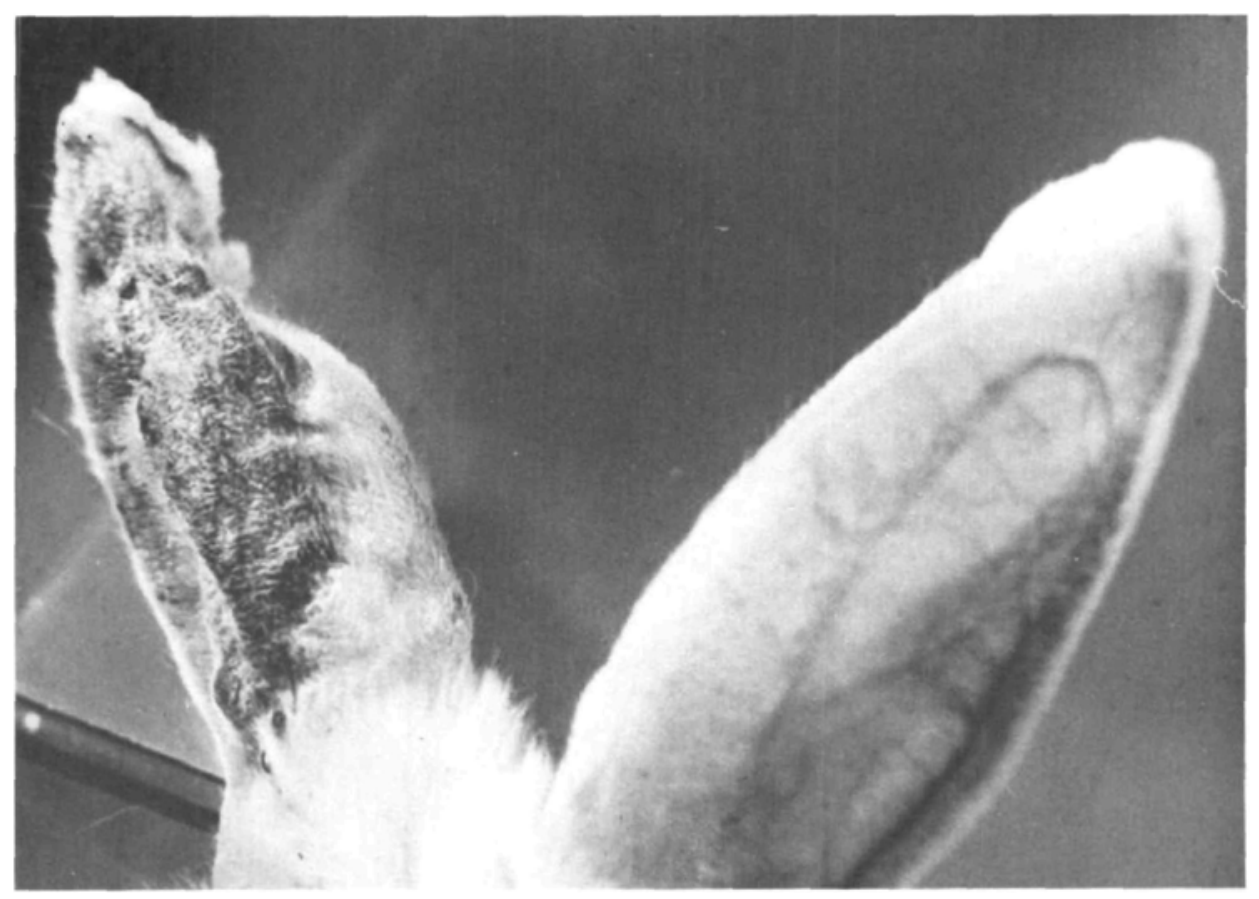

Figure 1. Gangrene of rabbit pinna following intra-arterial injection of diazepam. Pinna on the left was injected with diazepam ( 0.5 per cent) $1 \mathrm{mgm}, 14$ days prior to this photograph. The normal pinna on the right was injected with saline.

half. An area of necrosis appeared, frequently on the lateral edge of the distal portion of the pinna, about ten days after injection. Gangrene then spread to involve most of the pinna.

Microscopic sections, a few hours after injection, showed only vasodilation, and vascular congestion. The vessels appeared structurally normal. At five days there was interstitial œdema, with some extravasation of red cells and an inflammatory response about the vessels of the ear (Figure 2). Notably there were no thrombi in either small or large arteries or veins until seven to ten days post-injection, when gangrene was imminent.

Injection of the solvents of parenteral diazepam intra-arterially produced no pathological lesion. 


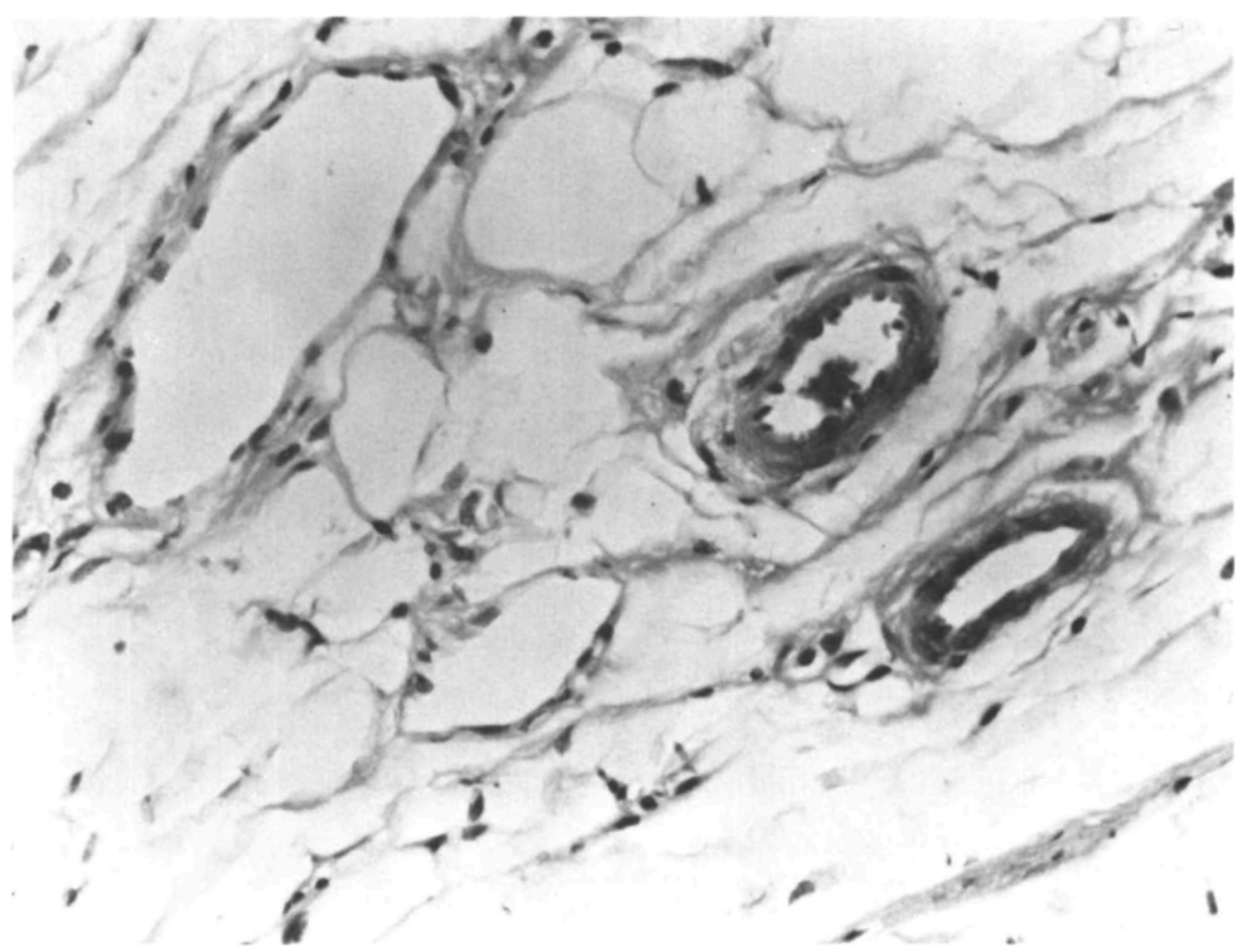

Figure 2. Cross section of pinna five days following intra-arterial diazepam. There is vascular dilatation and tissue cedema. Note patency of blood vessels.

\section{Doppler Flow Studies}

A pre-injection Doppler signal coinciding with the arterial pulse was heard and recorded. Following injection there was a short period during which no signal could be detected. (This did not necessarily indicate no flow at this time, only that the velocity of flow was below the sensitivity of the instrument.) After 15 to 20 minutes the arterial flow was detected once again, over both the central and peripheral vessels. Despite cedema formation, arterial flow could be detected over some vessels several days to a week post-injection.

\section{Electron Microscopy Study}

Sections prepared for electron microscopic examination were taken four hours following injections. There were significant differences in the electron microscopic pictures of pinnas injected with saline and diazepam. Saline pinnas were entirely normal. In the diazepam sections, there were arterioles and capillaries with distinctly abnormal endothelial cells (Figure 3 ). These cells were swollen and their external membranes were unusually folded. In some areas the plasma membranes appeared separated or fractured, with intra-cellular contents extruding. (Breakage of membranes can only be confirmed with tracer studies, which were not undertaken here.) Tight junctions appeared normal, as did intra-cellular organelles. These endothelial changes were patchy and some vessels appeared 

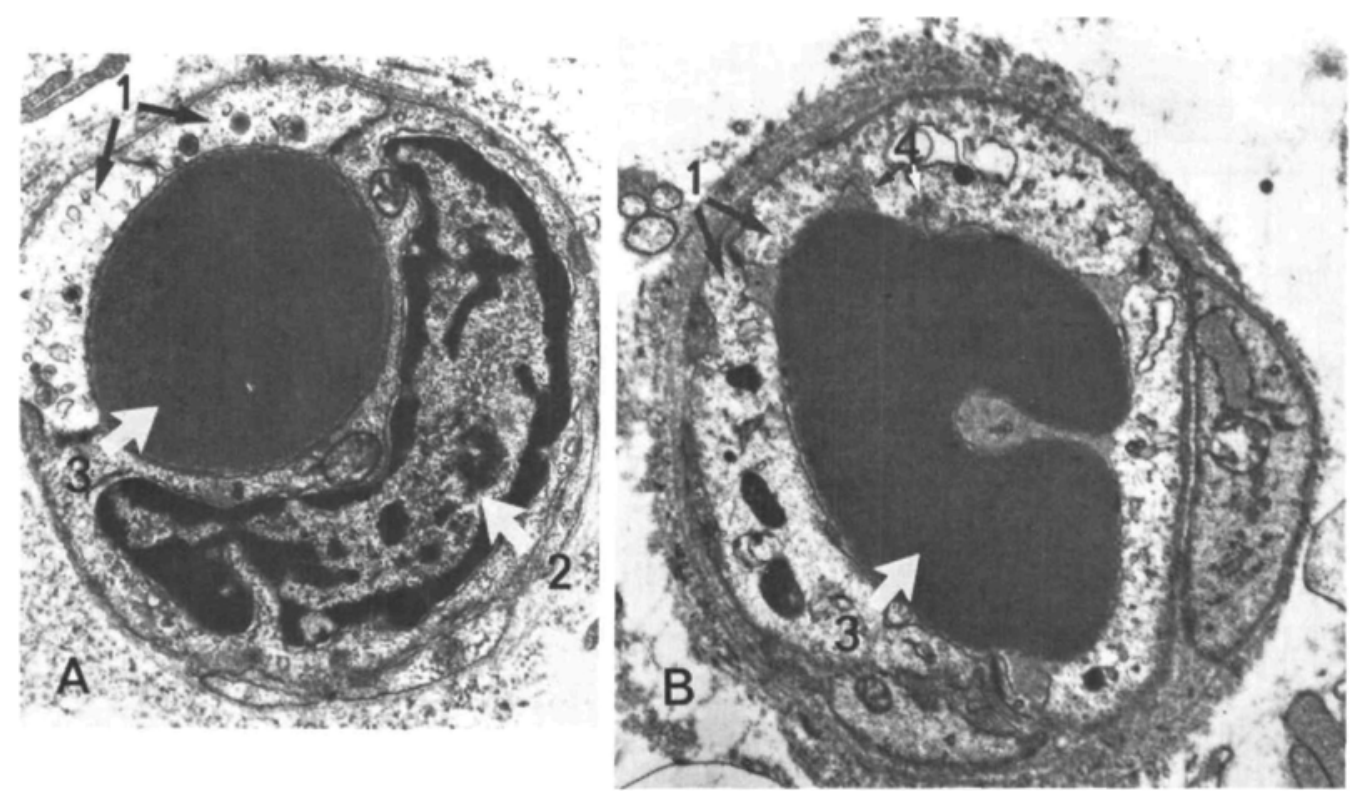

Figure 3. Electronmicrographs of rabbit pinna capillaries four hours after injections. (A) injected with saline. (B) injected with diazepam ( 0.5 per cent) $1 \mathrm{mgm}$ intra-arterially. Endothelial cells (1), an endothelial nucleus (2), and red blood cells in capillaries (3) are indicated. Section B shows considerable swelling of the endothelial cells with probable distuption of the plasma membrane at (4). Section preparations are described in text. Magnification approx. 20,000 times.

completely normal, presumably due to variation in exposure to the drug. Although some intra-capillary red cells were lysed, there was no evidence of small or large vessel obstruction. At this stage, tissues other than vascular appeared normal.

\section{Discussion}

Investigations of the pathological process following intra-arterial injections have classically used the rabbit pinna model. The method of some early investigators involved clamping the central artery of the pinna and injecting the drug distally into a static column of blood. ${ }^{15,16}$ The relevance of this to the clinical situation has been justifiably questioned. In this work, we have carefully avoided clamping or damaging the vessel (except for the needle puncture) and made our injections into a flowing stream of blood.

While there are obvious differences from the human fore-arm, the rabbit pinna is a reasonably good model for assessing tissue responses to intra-arterial drugs. The light and electron microscopic anatomy of its vasculature is identical to that of human vessels. In our laboratory, we have found that drugs inducing gangrene intra-arterially in man ( 0.5 per cent thiopentone, chlorpromazine, amphetamine), given in the same dosage per kilo are also destructive in this model. The gross and microscopic pathological changes in the pinna closely resemble those reported in man. Agents which are benign in man (2.5 per cent thiopentone, herapin, protamine) do not induce gangrene in the pinna. 
Drugs which may cause necrosis when injected into arteries (Table I) have high oil/water (or membrane/buffer) partition coefficients. In contrast, those which are safe intra-arterially (Table I) are much less soluble in oil and membranes at physiological $\mathrm{pH}^{11,12}$ We have found the highly membrane-soluble drug diazepam to be destructive to the pinna of the rabbit ear, whereas the less membranesoluble ketamine (water soluble to a concentration of 20 per cent) is not. (Other investigations have failed to observe gangrene following intra-arterial diazepam. ${ }^{17-19}$ However, the periods of observation in these studies were much shorter than the 10 to 14 days which we found was required for gangrene to appear.) These findings support our hypothesis that the membrane concentration of a drug could determine its potential for damage, when the drug is present in high concentrations in the arterial- and micro-circulations.

Popular theories suggest that barbiturates cause gangrene by acutely obstructing blood vessels. Thiopentone forms crystals of insoluble acid when mixed in high concentrations with blood. ${ }^{9}$ It has been proposed that, if formed in an artery, these crystals would block the downstream microcirculation, either mechanically ${ }^{9}$ or through thrombogenic effects. ${ }^{10}$ Although blockage of the circulation ultimately occurs, it is questionable whether it is the acute event. Pathological studies in both $\operatorname{man}^{4}$ and animals ${ }^{15}$ have shown that thrombosis may be delayed for days. A radiographic study of the rabbit pinna following intra-arterial injection of 10 per cent thiopentone showed patency of arteries and arterioles for 24 to 48 hours. ${ }^{20}$

We have proposed that damaging drugs might initiate their effect through a cytotoxic action on vascular endothelial cells. This hypothesis was strengthened by the pathological changes observed following intra-arterial diazepam. Although diazepam forms crystals when mixed with blood in vitro, light microscopy failed to demonstrate even minimal acute vascular obstruction in vivo, and patency was confirmed by Doppler detection of blood flow. Not until 7 to 10 days after injection was there early microscopic thrombosis and loss of flow detected by the Doppler. In the first few hours following intra-arterial diazepam, the only light microscopy findings were vascular dilatation and congestion; the arteries, arterioles and veins all appeared structurally normal. However, the electron microscope revealed an early lesion of the endothelial cells. Four hours after injection, arteriole and capillary endothelial cells were obviously swollen, and their membranes were distorted with a suggestion of breakage at some points (Figure 3). We attribute these findings to a membrane damaging effect of high concentrations of the drug, analogous to that which has been reported for membrane soluble drugs in vitro. ${ }^{12}$ This early disruption of some of the endothelial cells would explain the subsequent tissue œdema and perivascular inflammatory reaction which occurred without venous or arterial obstruction.

Consideration of the concentrations of drugs required for membrane lysis in vitro and the concentrations present after intra-arterial injection in man supports the hypothesis that membrane lysis could also occur in man. The lytic concentration of most membrane soluble agents bathing red cells in vitro is $10^{-1}$ to $10^{-2}$ moles per litre. ${ }^{12}$ We calculate that following injection of $10 \mathrm{ml}$ of 5 per cent thiopentone solution or $5 \mathrm{ml}$ of ( 0.5 per cent) diazepam into the human brachial artery, similar concentrations of these drugs (i.e., $10^{-1}$ to $10^{-2}$ moles per litre) would be bathing 
the plasma membranes of vascular endothelial cells, assuming a normal brachial artery flow of $40 \mathrm{ml}$ per minute and an injection time of 15 seconds. If these membranes react in a fashion analogous to human red blood cell membranes and rabbit endothelial cell membranes, then membrane lysis probably occurs.

The details of clinical reports of individuals (and animals) who have received intra-arterial barbiturates, phenothiazines or narcotics ${ }^{1-4}$ also support the theory that the fundamental process is one which initially causes leakage of the microcirculation, without vascular obstruction. During explorations of human limbs a few hours after intra-arterial thiopentone it was noted by Cohen that "the muscles bulged ... but were of normal colour and the œdema appeared not to have interfered with the blood supply." 4 Tissue œdema is a frequent early sign: after an initial period of vasospasm, the peripheral pulses are often preserved for several hours or days; and gangrene may take two or three weeks to appear. All these features are readily explicable by increased permeability or filtration of the microcirculation, with gradually increasing tissue œdema, vascular stasis, and then thrombosis and gangrene.

Several pathological studies have concluded that intra-arterial drugs are injurious through a direct irritant action on blood vessel walls. ${ }^{2,8}$ We have added a mechanism by which injury could occur, a mechanism which is consistent with several characteristics of the problem. Membrane lysis would require only brief contact of the drug with the membranes of the vessel wall, would explain increased permeability and vascular leakage, and would account for the difference in response of the circulation to membrane soluble and insoluble drugs.

In this report, we have only shown a relationship between intra-arterial diazepam and the structure and integrity of rabbit endothelial cells. Confirmation of a similar action of other membrane soluble agents in vivo is required. Our preliminary work with 5 per cent thiopentone is consistent. Although evolution of the pathological changes was more rapid ( 3 to 7 days for thiopentone vs. 10 to 14 days for diazepam), the sequence of events, i.e., endothelial damage (electron microscopic) followed by œdema, then thrombosis and gangrene, was identical. Again acute vascular obstruction was not seen. After injection of 2.5 per cent thiopentone there were no pathological changes, presumably because the lytic concentration of the drug in the blood was not achieved.

\section{SUMMARY}

We have demonstrated the toxicity of diazepam and the safety of ketamine hydrochloride following intra-arterial injection in an anaesthetized animal model.

The pathogenesis of gangrene following intra-arterial injection of drugs is unclear. Clinical reports and this experiment suggest that it only follows injection of highly membrane-soluble drugs.

Early swelling and disruption of capillary endothelial cells were demonstrated after intra-arterial injection of diazepam and thiopentone. We believe that a theory of pathogenesis based on this finding is consistent not only with our experimental findings, but with known in vitro effects of membrane soluble drugs on cell membranes and the clinical features following intra-arterial injections in both human subjects and in animals. 


\section{RÉSUMÉ}

Les auteurs ont démontré la toxicité du diazepam et la sécurité de l'hydrochlorure de kétamine à la suite d'injection intra-artérielle chez l'animal anesthésié.

La pathogénèse de la gangrène, provoquée par l'injection intra-artérielle de médicaments, n'est pas clairement définie. Les publications cliniques laissent croire que cette gangrène n'est provoquée que par des médicaments très solubles dans les membranes.

Le diazepam et le penthotal en injection intra-artérielle ont provoqué un œedème précoce et une rupture des cellules endothéliales des capillaires. Nous croyons qu'une théorie pathogénique fondée sur ces faits est compatible, non seulement avec les résultats de nos expériences, mais aussi avec les observations cliniques, de même qu’avec les effets démontrés in vitro de ces médicaments sur les membranes cellulaires.

\section{AdDendum}

Since the completion of this work, there has been a clinical report of gangrene of the fore-arm following an attempted intravenous injection of diazepam. Schneider, Sanford \& Mace, John W. Loss of Limb Following IntraVenous Diazepam. Paediatrics. 53: 112 (January 1974). The patient, a four-year-old child, was convulsing, and the diazepam was administered into the volar aspect of the wrist. The authors suggest that "it is possible that the infusion was inadvertently, at least in part, arterial."

The pathological sequence was swelling, cyanosis and then gangrene. Amputation of the fore-arm was required six days after the injection.

The hazards of inadvertent intra-arterial injection into a twitching limb are obvious. The potential necrotizing effect of the currently popular anti-convulsant diazepam should be appreciated.

\section{REFERENCES}

1. Gasper, M.R. \& Hare, R.H. Cangrene due to intra-arterial injection of drugs by drug addicts. Surgery 72: 573 (1972).

2. Engler, H.S., et al. Gangrenous extremities resulting from intra-arterial injections. Arch. Surg. 94:644 (1967).

3. Hager, D.L. \& WiLson, J.N. Gangrene of the hand following intra-arterial injection. Arch. Surgery 94: 86 (1967).

4. Conen, S.M. Accidental intra-arterial injection of drugs. Lancet 2: 361 (1948).

5. Enloe, G., Sylvester, M., \& Morris, L. Hazards of intra-arterial injection of hydroxyzine. Can. Anaes. Society Journal 16: 425 (1969).

6. Brmkhamn, H.J. \& Heifetz, M. Accidental intra-arterial injection of amphetamine. Brit. Journal of Anaes. 45: 761 (1973).

7. Goodman, L.S. \& Gilman, A. The pharmacological basis of therapeutics. Fourth edition. New York. Macmillan Co. (1970).

8. Stone, G.H. \& Donnelly, C.C. The accidental intra-arterial injection of thiopental. Anaesthesiology 22: 995 (1961).

9. WATERS, D.J. Intra-arterial Thiopentone; a physico-chemical phenomenon. Anaesthesia 21: 346 (1966).

10. Brown, S.S., Lyons, S.M., \& DundeE, J.W. Intra-arterial barbiturates. British Joumal of Anaesthesia 40:13 (1968).

11. Leo, A., Hansch, C., \& Elkins, D. Partition coefficients and their uses. Chemical Reviews 71: 525 (1971). 
12. Seeman, $P$. The membrane actions of anaesthetics and tranquillizers. Pharmacological Reviews 24: 585 ( 1972 ).

J3. RuUta, T. \& Collan, Y. Short-term effects of chlorpromazine on human leukocytes and erythrocytes. An electron microscopic study. Annales Medicinae Experimentalis et Biologiae Fenniae 50: 42 (1972).

14. Manufacturer's Information on "Ketalar" brand of ketamine hydrochloride and "Valium" brand of diazepam.

15. Kinmonth, J.B. \& Shepherd, R.C. Accidental injection of thiopentone into arteries. British Med. Journal 2: 914 (1959).

16. Francis, J.G. Intra-arterial methohexitone. Anaesthesia 19:501 (1964).

17. DoppMan, J.L., et al. Intra-arterial valium; its safety and effectiveness. Radiology 106: 335 (1973).

18. ChaI, C.Y. \& WANG, S.C. Cardiovascular actions of diazepam in the cat. Journal of Pharmacology and Exp. Therapeutics 154: 271 (1966).

19. Saita, T., Kozo, K., \& Okazaki, K. Accidental intra-arterial injection of an intravenous anaesthetic. Journal of Experimental Medicine 17: 1 (1970).

20. Ellertson, D.G., Lazarus, H.M., \& Awerbach, R. Patterns of acute vascular injury after intra-arterial barbiturate injection. American Journal of Surgery 126: 813-817 (1973). 